\title{
KNOWLEDGE MANAGEMENT VS \\ BUSINESS PROCESS MANAGEMENT \\ IN CONTEMPORARY ENTERPRISES
}

\author{
AGNIESZKA BITKOWSKA
}

\begin{abstract}
A B S TR A C T
The main objective of this paper is to identify the system of knowledge management in contemporary process organizations in business process perspective, especially with regard to technological and social conditions. Methodology is based on literature analysis and case studies. The integration of knowledge management technologies, concepts and methods into organizational business processes is challenging research issue today. The concepts of knowledge management and business process management should be analyzed jointly in the contemporary enterprises. Despite of the growing interest among researchers and practitioners of the concept of the knowledge management referring to business process management there is a lack of articles in this area. Appropriate approach to the modelling of knowledge management processes, as well as the use of IT tools, and a motivation system are of key importance for the introduction of this solution in organizations.
\end{abstract}

KEY WORDS

knowledge, knowledge management

DOI: 10.1515/emj-2016-0014
Corresponding author:

Agnieszka Bitkowska

University of Finance and Management in Warsaw, Faculty of Management, Poland

e-mail: pbab@wp.pl

\section{INTRODUCTION}

Technological development has caused an enormous increase in the importance of knowledge possessed by companies. Enterprises that place emphasis on knowledge development have started to be successful, which has contributed to seeing knowledge as a very important resource that brings about measurable benefits. Therefore, a natural necessity to measure, describe, and manage knowledge has emerged, which resulted in the development of a term - knowledge management. Knowledge management itself had, of course, been present in organizations intrinsically for years, however, the need to name and examine this phenomenon more deeply has emerged.

Process management in an organization should take into account the knowledge resources that the organization possesses in order to ensure that employees have access to knowledge regarding specific tasks which are part of particular business processes (Maier \& Remus, 2002, p. 103). The key factors causing all processes in an organization to run smoothly are learning and cooperation. Support of IT tools is necessary too. Therefore, the processes occurring in an organization should be increasingly based on individual, team, and organizational knowledge and, consequently, become more and more flexible as well as adjusted to the changing environmental conditions (Richter-von Hagen et al., 2005). It is necessary to indicate knowledge resources, which are key in a contemporary organization, by way of creating an organizational knowledge management model. An appropriate attitude of employees and willingness to transfer and share 
knowledge are also important.

\section{KNOWLEDge Management}

The nature of knowledge management may be seen from at least four different perspectives. In the functional approach, it is a process consisting in performing the management function focused on knowledge resources and processes in which they take part and the conditions necessary to carry those processes out in a manner that ensures efficient accomplishment of an organization's objectives. In the process approach, it is normative and dispositional activity intended to create appropriate environment which allows effective performance of tasks related to knowledge management. In the instrumental approach, it denotes the selection and application of (social, technical, organizational, economic-financial, and legal) instruments that contribute to the course of the main processes that knowledge participates in at all levels and areas of an organization. Finally, in the institutional approach, it is a system of positions and employee teams that perform the functions related to knowledge management (Potocki, 2011). This shows the complexity of knowledge management and the abundance of its elements which need to be taken into consideration in the course of knowledge management. Taking all its aspects into account is an objective that should be aspired to in order for a modern organization with a system of knowledge management to be created.

The concept of a company based on knowledge (oriented at knowledge) seems to meet the contemporary challenges that a model of an organization is faced with, especially in terms of flexible mechanisms of reacting to instability and changes in the environment by way of efficient collection, development, and processing of knowledge about individual and institutionalised clients, existing and future competition, business partners, existing and potential suppliers, individual employees, resources, the inner capacity of an enterprise, the socio-economic conditions, political and legal circumstances, modern technologies, or new management methods (Morawski, 2006). In contemporary companies one may observe, in some sense, a decrease in the value of fixed assets, such as inventory or capital and an increase in the importance of non-material assets, such as competences or professionalism which are constituents of knowledge.
The number of enterprises whose worth is determined by their capital and material possessions is constantly decreasing; increasingly, however, success is ensured by the fact that a company has very special assets, such as: collected knowledge, know-how, or utility models. Knowledge management in a company allows to determine the value of an organization as a whole and not just its material assets.

In an enterprise engaged in knowledge management, considerable emphasis is placed on knowledge acquisition, its proper dissemination, application for the benefit of the company, and transformation of knowledge into a service or a product. An enterprise development plan contains knowledge management strategies, directions of development, and possibilities for introducing changes for the purpose of producing the desired results. Introduction of knowledge management allows to notice the processes taking place in a company. For instance, it is possible to observe the influence of knowledge acquisition by employees through various forms of education. The very possibilities of observing the stages of a process - first acquisition of knowledge, then dissemination and sharing - as well as the relationships between the stages and the obtained results from the specific nature of knowledge management in an organization.

Effective knowledge management in an organization allows to (Skrzypek, 2012):

- comprehensively aid organizations in collecting, analysing, and applying knowledge in order to make effective decisions strengthening the company's market position,

- apply employee knowledge for the purpose of producing - in line with the principle of reasonableness - optimal effects and market success in the long run,

- achieve managerial effectiveness which is the fundamental element of the striving for the effectiveness and the development of an organization,

- create an infrastructure which allows efficient use of knowledge resources by all the members of an organization,

- offer opportunities for identification and practical application of knowledge in an organization in order to ensure financial, market, dynamic, and operational effectiveness,

- effectively use theoretical knowledge and the experiences that an organization have gained,

- skilfully use knowledge in order to perform tasks correctly and thus avoid mistakes,

- effectively use the knowledge of all participants to 
the extent that contributes to the improvement of an organization's position,

- create a database that makes it possible to acquire, broaden, improve, and apply the available knowledge in practise,

- create an atmosphere facilitating the sharing of the information obtained by an organization among the employees,

- define and also solve problems and subsequently implement the solutions at an optimal level of costs as well as activate the learning processes in all the employees.

Therefore, the nature of knowledge management is comprised of the following stages: knowledge creation, dissemination, and application. These stages are supported by introducing management strategies oriented at people, which give them freedom to act and exchange knowledge. Management should encourage people to willingly share their knowledge, while taking into consideration their cultural needs, social values, aspirations, affinities, and tastes. If such factors are taken into account, it steers employees to create new knowledge in an organization. This is because it is impossible to create knowledge solely from the information that one has without the participation of people and thus people are a significant and necessary factor in knowledge management. A major role is also played by computer systems supporting decision-making and measuring the effectiveness of application of an organization's resources. Computer systems are tools allowing to transform large amounts of data into easily accessible information. The use of computer systems causes all the aspects of knowledge management to work smoothly and in a coordinated fashion. Knowledge management reduces the time that is needed to perform a task and prevents duplication of work; it also allows to obtain knowledge from the competition as well as find and counteract bottlenecks that hamper the flow of knowledge within an organization.

Knowledge is present in any company, however, not every organization manages knowledge in a formalized manner, which often leads to losing it. Effective knowledge management requires a proper method to be created. Division into revealed and hidden knowledge also causes trouble with respect to answering the question: how to manage knowledge? Knowledge management serves to use an organization's resources in the best possible way in order to improve its operation and accomplish its objectives. This contributes to an effective application of the knowledge resources that an organization possesses. It also allows to organize the knowledge that an organization possesses and formulate a strategy for obtaining new knowledge as well as formalizes the principles governing dissemination of knowledge.

Knowledge management takes place with respect to individual employees and teams; hence it exerts influence all the management areas, including issues related to the staff, company development, or computerization. Comprehensive knowledge management produces the effect of reinforcement of the relationships among employees or groups and the structure of a company. C. Soo, T. Devinney, D. Midgley, and A. Deering (2012) describe a knowledge management system comprised of four subsystems:

- databases - allowing employees and manages to share information and efficiently shape the repositories of information,

- organizational language - enabling people to understand the state of affairs. It is connected with decoding the information obtained from databases, codification of ones' own knowledge into data that are easily accessible and used by others, and a language system that allows people in an organization to gain deep understanding of the messages received during the process of verbal and non-verbal communication,

- network links - enabling people to receive and digest information and knowledge from sources located inside the organization as well as outside it. The subsystem of net links services both the formal and informal levels of an organization,

- transfer - used to transfer knowledge among people, or as a result of a rare combination of pieces of information derived from an individual source of experiences, new knowledge is created.

In order to implement a knowledge management system and achieve best possible results on account of this system, it is necessary to use appropriate organizational and technological tools; ensure an ICT structure and a software structure embedded in the former. Such tools enable easier, faster, and, first and foremost, more efficient knowledge management. They also allow knowledge contained in documents, notes, reports, and employee communication to be created, organized, and shared. In the layer that is invisible for the end user, these tools are often based on such systems as SQL server, Oracle, SAP, Lotus Notes, Microsoft Server, and many more. Depending on the needs of a given organization, it may choose one of the systems available on the market. The selection of a given system or several systems 
determines the manner of knowledge management in a particular organization. The methods may be divided into knowledge management with the use of: documentation management, a website, knowledge maps, databases, teams exchanging experience, or various forms of cooperation.

One of the means of knowledge management in an organization is using models, and the choice of a model depends on the character of the organization's operations. The resource-based model, where knowledge is treated as the key resource, is based on knowledge sources, qualifications, and competences. The process model used mainly by large organizations is based on methods proven in practice. There is also the so-called Japanese model.

It is immensely important to use knowledge that is very varied, acquired in various ways, often hidden or even out-of-date; it is thus necessary to adopt a systemic approach to knowledge and its everyday application. Knowledge should be managed by means of a system that may offer the possibilities for its application at the right time and by appropriate people. The management staff in an organization is of considerable importance for companies; it should hold a belief that knowledge is a very significant asset and it is worth managing it, for it may translate into the pace and power of growth and development of an organization. Motivation of employees to acquire and share knowledge is also important (Moczydłowska, 2015). A knowledge management system that is properly built, used, and supervised certainly contributes to the ultimate success of an organization.

Knowledge management systems in a company should meet the following requirements (Haraf \& Wójcik, 2015):

- facilitate collection of knowledge,

- prevent loss of knowledge due to labour turnover,

- enable continual improvement of core skills,

- ncrease the effectiveness of managing the process of new knowledge acquisition,

- allow employees to share knowledge.

Therefore, the possibilities for using knowledge are largely determined by the processes of sharing and disseminating it. One should bear in mind that employees themselves possess valuable hidden knowledge that they might share with others. In order to improve the effectiveness of dissemination of knowledge, an organization should make staff members aware that the value of knowledge is relative (Probst et al., 2002). There are many reasons why a formal system of knowledge management should be introduced in a company. Undoubtedly, knowledge management brings about benefits for contemporary enterprises. If companies have codified knowledge resources, they may reap the benefits of them, such as learning by individual employees as well as teams. As far as the internal advantages for the enterprise are concerned, the following may be observed:

- free flow of information inside the organization, exchange of experiences among employees and project teams,

- development of employees' skills, using their experiences, appropriate motivation of staff members, and sharing knowledge,

- using employees' creativity and ideas as well as innovative solutions,

- changes in terms of the flow of information between departments in a company, resulting from the introduction of appropriate procedures,

- reaction to changes occurring in the environment and faster decision making.

- Whereas the external benefits of knowledge management encompass:

- development of an organization, creation of new organizational and product improvements,

- competitiveness on the market and continuous improvement of employees' qualifications,

- effective operation of an organization, cost cutting,

- adjustment to market needs,

- constant observation of clients' needs and the activity of the competition,

- continuous enhancement of the quality of products or services and creation of new ones,

- significant changes in the shaping of relationships with clients, suppliers, and partners on the market,

- creation of a positive image.

Employees serve an important role in a company as they determine the way it is seen by clients. Therefore, companies should strive to develop the competences and qualifications of their staff. A rise in employees' competences exerts a positive influence on their frame of mind. A worker who has knowledge feels appreciated and integrated with the company. Such a situation influences the self-realization of an employee and their creativity. This causes an increase in competitiveness of staff members on the market. The benefits arising from knowledge management have an impact on the relationships with business partners and the competition. They are reflected in the exchange of experiences and willingness to share one's ideas (Bartol \& Srivastava, 2002). This leads to a better understanding of clients' needs and influences the improvement in products or services. 


\section{BUSINESS PROCESS MANAGEMENT}

Process management has become an inspiration and foundation of many research as well as application initiatives over more than a dozen recent years. As far as the theory of management is concerned, one of the trends in organization management is process approach which comprehensively and horizontally attends to the structure of an organization. In this approach, the selected elements of an organization are coordinated by a manager of a given business process, who is responsible for the supervision and coordination of the course of this process.

Business process management (BPM) is a field in operations management that focuses on improving corporate performance by managing and optimising a company's business processes. It can therefore be described as a "process optimization process". It is argued that BPM enables organizations to be more efficient, more effective and more capable of change than a functionally focused, traditional hierarchical management approach. These processes can impact the cost and revenue generation of an organization.

There are 4 Process Methodologies of BPM (Chong et al., 2010):

- Total Quality Management,

- Six Sigma,

- Lean,

- ISO 9001.

Organizations are traditionally designed and managed in a functional sense with the organization chart. Whether it may be a hierarchal, functional, and divisional or matrix system, the focus is on managing defined entities within the chart. However entities by themselves cannot deliver external value. Value is collectively created by the collaboration between these functional entities.

Hence the idea of looking "outside in" has been used as the basis for bridging the gap between corporate strategies and process strategies. From this, it can be identified that the precursors of corporate strategies are derived from external stakeholders, or customers (Selden \& MacMillan, 2006). For instance business drivers such as efficiency, effectiveness and agility are examples of internal goals driven by the need to deliver value to customers.

Organizations across a wide range of market areas, in particular the highly competitive service sector, are realizing that core process are valuable assets. As a result they have embarked on projects based on utilizing BPM to fuel the delivery of corporate strategies. This article will examine theoretical frameworks underpinning the management of strategies.

The improvement in clients' satisfaction and the effectiveness of services and decision making must also be highlighted. Knowledge is the inseparable resource processed as part of processes. Knowledge is generated when organizational processes take place, such as: distribution, marketing, designing, and preparation of production. As far as knowledge created in the course of the processes of designing and preparation of production is concerned, it is technical in character (Hofman \& Skrzypek, 2010). One of the main reasons behind process deferral is lack of appropriate information or knowledge that are unavailable at the right moment, which causes a process to stop, employees to engage more fully, and costs to increase (Bitkowska, 2010). Knowledge is put to use by both the performers of processes - process team members - as well as the owners of processes. Moreover, information about the course of a process and the achieved results is becoming organizational knowledge. Any information related to processes, such as: process model, indicators, measures, and aims, should be collected and formalized in order to contribute to the improvement and consequently the development of the whole organization (Bitkowska, 2015). Modelling of the process of knowledge management is a tool for generating, collecting, and disseminating organizational knowledge.

A major role in knowledge management is played by information technologies, management systems, attitude of the staff, and organisational culture that arouses enthusiasm and eagerness of staff members, which contributes to knowledge sharing and creation of the so called „project teams”. The strategy pursued by an organization, its employees, technology, and organizational culture underlies the process of knowledge management, in particular: creation, codification, and transfer of knowledge. Knowledge management should be based on three fundamental pillars: people, technology, and processes.

\section{CONCLUSIONS}

Recently, deeper and deeper changes in both technology and politics, as well as social and economic advancement, have contributed to the emergence of a new type of the economy, the so-called knowledgebased economy. The above-mentioned mechanism 
has compelled the development of a new way of thinking and forced organizations to seek novel manners of operation. In contemporary organizations, greater and greater stress is being placed on acquisition of knowledge, its proper sharing, and application. Since the immense significance of knowledge in process approach was acknowledged, it has become necessary to develop systems supporting creation and application of knowledge.

The benefits accruing from the implementation of the knowledge management in an organization are concerned with, among other things, creation and adoption of new ideas, making knowledge resources available to appropriate people at the right time and place, facilitation of seeking and application of specialized knowledge and know-how, support for cooperation, communication, sharing knowledge, and continuous learning and improvement by individual employees and the whole organization.

Knowledge management in an organization is closely related to process management. Identification, acquisition, presentation, and documentation of knowledge are not independent tasks but inner elements of economic processes. Therefore, the point of departure for management of knowledge resources in an organization is understanding of the processes taking place in the organization. Implementation of the model of the knowledge management process influences generation of innovation, stimulation of creativity of staff members, and support for internal communication. Appropriate approach to the modelling of knowledge management processes, as well as the use of IT tools, and a motivation system are of key importance for the introduction of this solution in organizations. Despite periodical shifts in interest evinced in the topic, the deliberations on process management in organizations and the analysis that has been carried out are both fascinating and needed. Wide interest in this field evinced by theoreticians and practitioners testifies to that. Process management is considered to be an up-todate approach to an organization's operation, while process structures offer a sense of order. Knowledge management in organizations may not be separate from management of organizations' processes. It is easier for organizations using process management to model knowledge management processes; knowledge is collected in databases of processes in repositories. There are knowledge resources and they are used, modified, shaped, and perpetuated. There are also relations based on knowledge sharing, which are part of the informal organizational culture. The prepared process of knowledge management is intended to systematize these informal rules and relations existing in process-based organizations and make them objective. The aim is to acquire, process, store, and distribute knowledge. The most significant actions in this contexts should be oriented at adoption of IT systems supporting the modelling of the process of knowledge management. IT tools are supposed to ensure that the knowledge management process is run effectively, the IT tools are introduced into the knowledge process management (planning, coordinating, monitoring, and accounting for), and organizational culture fostering trainings and cooperation among the staff members is being built. Coping with this sphere and its operationalization by means of specific strategic, structural, technological, and personal solutions constitute a challenge for each and every process-based organization.

\section{LITERATURE}

Bartol, K., \& Srivastava, A. (2002). Encouraging knowledge sharing: The role of organizational reward systems. Journal of Leadership and Organization Studies, 19(1), 64-76.

Bitkowska, A. (2010). Business Process Management orientated towards creation of knowledge in enterprise. Proceedings of 2nd Annual International Conference on Sustainable Enterprises of the Future. Pittsburgh, USA: Robert Morris University.

Bitkowska, A. (2015). The Orientation of Business Process Management toward the Creation of Knowledge in Enterprises. Human Factors and Ergonomics in Manufacturing \& Service Industries, 25(1), 43-57.

Chong, A. Y. L., Ooi, K. B., Lin, B., \& Teh, P. L. (2010). TQM, knowledge management and collaborative commerce adoption: A literature review and research framework. Total Quality Management \& Business Excellence, 21(5), 457-473.

Haraf, A., \& Wójcik, M. (2015). Zarządzanie wiedza przepustka do sukcesu w biznesie [Knowledge Management - a Passport to Success in Business]. Retrieved fromhttp://www.pi.gov.pl/PARP/chapter_86196.asp?

Hofman, M., \& Skrzypek, E. (2010). Zarzadzanie procesami w przedsiębiorstwie [Process management in enterprise]. Warszawa, Poland: Wolters Kluwer.

Maier, R., \& Remus, U. (2002). Defining process-oriented knowledge management strategies. Knowledge and Process Management, 9(2), 103-118.

Moczydłowska, J. M. (2015). Nowe oblicze procesu kadrowego - uwarunkowania zmian [The new face of personnel process - conditions of changes]. In A. Bitkowska, E. Weiss (Eds.), Metody podejścia procesowego $\mathrm{w}$ organizacjach. Teoria i praktyka [Methods of process approach in organizations. Theory and practice]. Warszawa, Poland: VIZJA PRESS\& IT. 
Morawski, M. (2006). Celowość tworzenia zintegrowanego systemu zarządzania pracownikami wiedzy [The Advisability of Creating the Integrated System of Management of Workers of Knowledge]. Prace Naukowe Akademii Ekonomicznej we Wrocławiu, 1104, 165-173.

Potocki, A. (Ed.). (2011). Komunikacja w procesach zarzadzania wiedza [Communication in Knowledge Management Processes]. Kraków, Poland: Fundacja Uniwersytetu Ekonomicznego w Krakowie.

Probst, G., Raub, S., \& Romhardt, K. (2002). Zarządzanie wiedza $w$ organizacji [Knowledge Management in an Organization]. Kraków, Poland: Oficyna Ekonomiczna.

Richter-von Hagen, C., Ratz, D., \& Povalej, R. (2005). A Genetic Algorithm Approach to Self-Organizing Knowledge Intensive Processes. Proceedings of I-KNOW '05, Graz, Austria.

Skrzypek, E. (2012). Strategia rozwoju społecznej gospodarki rynkowej w Polsce [Development Strategy of Social Market Economy in Poland]. Lublin, Poland: Wydawnictwo Uniwersytetu Marii CurieSkłodowskiej.

Soo, C., Devinney, T., Midgley, D., \& Deering, A. (2012). Knowledge Management: Philosophy, Processes, and Pitfalls. California Management Review, 44(4), 129-150.

Vaccaro, A., Parente, R., \& Veloso, F. M. (2010). Knowledge management tools, inter-organizational relationships, innovation and firm performance. Technological Forecasting and Social Change, 77(7), 1076-1089. 